\title{
Use of a Blood Gas Analyzer to Measure Blood Hemoglobin During Liver Transplantation: A Study of 935 Paired Samples
}

\author{
L. Rivas Chirino, J. da Silva Viana, C.A. Tavares, A. Palmeiro, and F.J. Oliveira
}

$\mathrm{L}^{\mathrm{I}}$ IVER TRANSPLANTATION is associated with significant blood loss and frequent variations in blood hemoglobin concentrations. The administration of red blood cells (RBC) under strict rules supported by the hemoglobin values is an important strategy to reduce blood consumption. The rapidity of the analytic response is important for an appropriate transfusion policy.

In general, blood gas analyzers measure hemoglobin concentrations accurately and are contiguous to operating rooms, contrary to standard Coulter analyzers, which are usually located in central hospital laboratories. The use of blood gas analyzers to measure hemoglobin has the advantage of rapidity, as there is no time wasted in transport. Additionally, a reduction in laboratory samples has economic advantages and spares patient blood.

Some previous studies compared blood gas analyzers with standard laboratory Coulter analyzers, ${ }^{1,2}$ however, as far we know, this was never done specifically in liver transplantation, in young children, at low levels of hemoglobin, or with high levels of bilirubin, factors which could influence the results. We performed this study with the purpose of evaluating the accuracy of a blood gas analyzer to measure hemoglobin in these specific conditions.

\section{PATIENTS AND METHODS}

With institutional approval, this study included blood samples collected during orthotopic liver transplantation, from 1998 to 2003. A total of 935 pairs of samples were collected during 314 transplantations (277 first transplantations and 37 retransplantations performed in 199 male and 115 female patients of ages between 6 months and 63 years $(33.8 \pm 16.1$ years), weight from 5 to $109 \mathrm{~kg}(59.7 \pm 21.3 \mathrm{~kg})$, and preoperative total bilirubin from 0.2 to $49.5 \mathrm{mg} / \mathrm{dL}(7.1 \pm 10.3 \mathrm{mg} / \mathrm{dL}$; median, $2.2 \mathrm{mg} / \mathrm{dL})$. The paired samples were collected from liver transplant patients during a 6-year period.

The methodology was the following: from an arterial line (a radial artery in the great majority of cases) the blood was obtained in a sufficient volume to prevent dilution with saline used to flush the line. In an immediate sequence, blood was aspirated with a $10 \mathrm{~mL}$ syringe and a $1 \mathrm{~mL}$ sample was then collected with a preheparinized syringe PICO 70 with 60 UI of electrolytebalanced heparin. Three milliliters of blood from the $10 \mathrm{~mL}$ syringe were immediately injected to an appropriate tube with citrated anticoagulant (EDTA - tripotassic tetra acetic ethyledinodiamine), reference K3E (BD Vacutainer, Plymonth, UK), to be sent to the hospital central laboratory where calcium chloride was added to the sample before centrifugation. Measurements of hemoglobin were performed with a Beckman Coulter LH 750. This laboratory is certified for this purpose by an independent Quality Agency (BVQY). The blood in the heparinized syringe was immediately analyzed in a contiguous laboratory with an ABL 505 (Radiometer, Copenhagen) connected to an OSM3 device. The routine maintenance of this equipment is the responsibility of the operating room staff. In children, the following differences existed compared with the above description: samples for blood gas analysis and laboratory hemoglobin analysis were only $0.5 \mathrm{~mL}$. Syringes for blood gas were the same, but tubes for laboratory analysis were reference CAPiject (Terumo).

\section{Statistical Analysis}

The Bland-Altman method $^{3}$ was used to evaluate differences between the two methods. By multiple regression analysis we estimated the difference related to hemoglobin laboratory values as dependent upon age or preoperative bilirubin. Comparisons between groups were done with the Mann-Whitney test. Data were analyzed with SPSS, version 9.0. Data are presented as mean values \pm standard deviations.

\section{RESULTS}

The number of paired samples collected in one isolated transplant ranged from 1 to $15(2.98 \pm 1.46$ pairs of samples). Values of hemoglobin obtained with the blood gas analyzer $(9.47 \pm 1.74 \mathrm{~g} / \mathrm{dL})$ were, on average, higher than those obtained in the laboratory $(9.17 \pm 1.7 \mathrm{~g} / \mathrm{dL})$. In $8.1 \%$ of the samples, the former equipment overestimated the laboratory value by more than $1 \mathrm{~g} / \mathrm{dL}$, but only in $0.3 \%$ of cases did it underestimate the laboratory value by more than $1 \mathrm{~g} / \mathrm{dL}$. The average difference between the two types of equipment was $0.30 \pm 0.56 \mathrm{~g} / \mathrm{dL}(0.95 \mathrm{CI}=0.27-0.34$ $\mathrm{g} / \mathrm{dL})$. Nevertheless, the two methods correlated well $\left(r^{2}=\right.$ $.90, P<.0001)$. Bland-Altman plots of the relation between the difference in each pair of values and the respective mean hemoglobin value are shown in Fig 1 . The 95\% CI for

From the Faculty of Medicine, University of Coimbra and University Hospitals of Coimbra, Coimbra, Portugal.

Address reprint requests to Dr Lorena Rivas Chirino, Department of Anesthesiology, University Hospitals of Coimbra, Praceta Mota Pinto, 3000-075 Coimbra, Portugal. E-mail: lorenarch@ hotmail.com 


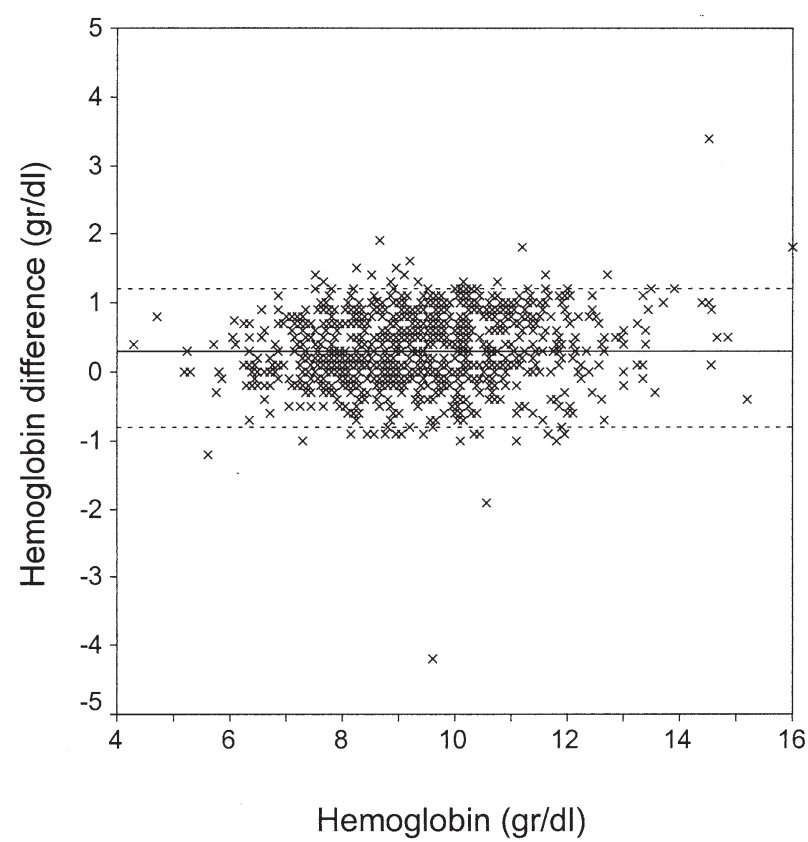

Fig 1. Plot of the differences between each pair of values and the mean value of the pair $\left(r^{2}=.0003, P=.64\right)$. The straight line is the mean of differences; included between the dotted lines are $95 \%$ of the observed differences.

lower limit of agreement was -0.88 to $-0.76 \mathrm{~g} / \mathrm{dL}$ and for upper limit was 1.36 to $1.49 \mathrm{~g} / \mathrm{dL}$ (mean $\pm 2 \mathrm{SD}$ ).

From the whole study, 216 pairs of samples $(23.1 \%)$ were collected in patients with hemoglobin levels from 4.1 to 8.0 $\mathrm{g} / \mathrm{dL}$. No correlation was found between the differences in the two methods and the respective values of hemoglobin $\left(r^{2}=.0003, P=.64\right)$. The discrepancy between equipment was similar when we compared the subgroup of patients with hemoglobins lower than $8.0 \mathrm{~g} / \mathrm{dL}(0.31 \pm 0.47 \mathrm{~g} / \mathrm{dL})$ and the subgroup with hemoglobins higher than $8.0 \mathrm{~g} / \mathrm{dL}$ $(0.30 \pm 0.59 \mathrm{~g} / \mathrm{dL} ; P=.86)$.

From 148 pairs of samples $(15.8 \%)$ collected in children aged 6 months to 10 years ( $46 \%$ of these up to 2 years old), we observed that the differences between the two types of equipment was slightly less $(0.15 \pm 0.59 \mathrm{~g} / \mathrm{dL})$ than that in adults $(0.33 \pm 0.55 \mathrm{~g} / \mathrm{dL} ; P=.0005)$.

Finally, 205 pairs of samples $(21.9 \%)$ were collected from patients with total preoperative bilirubin values equal to or higher than $10 \mathrm{mg} / \mathrm{dL}$. The discrepancy in the values of hemoglobin between the two types of equipment was similar when we compared the subgroup of patients with preoperative bilirubin higher than $10 \mathrm{mg} / \mathrm{dL}(0.25 \pm 0.59$ $\mathrm{g} / \mathrm{dL}$ ) and the subgroup with preoperative bilirubin lower than $10 \mathrm{mg} / \mathrm{dL}(0.32 \pm 0.55 \mathrm{~g} / \mathrm{dL} ; P=.22)$. No correlation was observed between the differences in the two methods and the respective values of bilirubin $\left(r^{2}=.005\right)$.

\section{DISCUSSION}

We compared a blood gas analyzer with a traditional Coulter counter for the measurement of hemoglobin in 935 samples collected during 314 liver transplants. We concluded that the former equipment was useful for hemoglobin evaluation in settings where rapidity of analysis is important. We observed that blood gas equipment tended to overestimate the laboratory values, but the average difference was small and the differences not of sufficient magnitude to impact therapeutic decisions with regard to the administration of blood. However, in a small percentage of cases, the overestimate reached a degree that deserved some attention.

Our results are similar to those published by others, ${ }^{2,3}$ however, as far as we know, our study is the first to include patients with high values of bilirubin and a significant percentage of pediatric cases. It has previously been reported that bilirubin interferes with hemoglobin measurements. ${ }^{4}$ Our study demonstrated that hyperbilirubinemia was not a factor for the divergence between the Coulter analysis and the blood gas analysis of hemoglobin. Although our study did not have the ability to evaluate whether bilirubin disturbed hemoglobin measurements, we can say that, if this occurs, the interference is similar in the two types of equipment.

Concerning pediatric cases, it may be hypothesized that blood sampling in small children could increase the error in hemoglobin measurements. Our study found the opposite, and differences between the two types of equipment were smaller and virtually negligible in the pediatric cases. A possible explanation is the special care in taking blood samples in children.

In the absence of another logical justification to the overall discrepancy that we observed between the two types of equipment, the finding that the difference was smaller in children than in adults supported the possibility that discrepancies were related more to the collection, handling, and transport of the samples than factors exclusively related to the equipment.

\section{ACKNOWLEDGMENT}

We thank Prof Manuel Antunes for advice during preparation of the manuscript.

\section{REFERENCES}

1. Ray JG, Post JR, Hamielec C: Use of a rapid arterial blood gas analyzer to estimate blood hemoglobin concentration among critically ill adults. Crit Care 6:72, 2002

2. King R, Campbell A: Performance of the radiometer OSM3 and ABL505 blood gas analysers for determination of sodium, potassium and haemoglobin concentrations. Anaesthesia 55:65, 2000

3. Bland JM, Altman DG: Statistical methods for assessing agreement between two methods of clinical measurement. Lancet $1: 307,1986$

4. Lampert R, Brandt L: The effect of hyperbilirubinemia on the measurement of oxygenated hemoglobin $(\mathrm{O} 2 \mathrm{Hb})$, carboxyhemoglobin $(\mathrm{COHb})$ and methemoglobin $(\mathrm{MetHb})$ using multiwavelength oximeters in mixed venous blood. Anaesthesist 42:702, 1993 